\title{
Integrating Content and English-Language Learning in a Middle Eastern Information Technology College: Investigating Faculty Perceptions, Practices and Capabilities
}

\author{
Norman Williams, John C. Beachboard, and Robert Bohning \\ Zayed University, Abu Dhabi, UAE
}

\author{
norman.williams@zu.ac.ae john.beachboard@zu.ac.ae \\ robert.bohning@zu.ac.ae
}

\begin{abstract}
The expanding role of English as an international lingua franca has had considerable effects on higher education (HE) provision around the world. English has become the medium of choice for African HE, and its position as a medium of instruction in the Europe and Asia is strengthening (Coleman, 2006; HU, 2009). English-medium tertiary education is also commonplace in the Middle East including the United Arab Emirates (UAE), the context of the present study, where the vast majority of courses at university-level are conducted in English (Gallagher, 2011). The increasing use of English-medium programs presents particular challenges for content-area faculty who are in effect called upon to provide disciplinary instruction to students who may not be adequately language proficient. Furthermore, discipline-specific faculty may find themselves sharing responsibility to further develop their students' English language proficiency. Information technology related schools face unique challenges. A significant majority of IT faculty come from computer science/engineering backgrounds and speak English as a second or third language. Most courses emphasize the development of technical skills and afford relatively few opportunities for writing assignments. While exploratory in nature, the study proposes to identify and evaluate practices that can help IT colleges better develop their students' proficiency in English.
\end{abstract}

Keywords: IT Education, English-medium university courses, English-medium teaching in higher education, multilingual language policy, content and language integrated learning (CLIL), STEM courses, English for Academic Purposes (EAP).

\section{Introduction}

Material published as part of this publication, either on-line or in print, is copyrighted by the Informing Science Institute. Permission to make digital or paper copy of part or all of these works for personal or classroom use is granted without fee provided that the copies are not made or distributed for profit or commercial advantage AND that copies 1) bear this notice in full and 2) give the full citation on the first page. It is permissible to abstract these works so long as credit is given. To copy in all other cases or to republish or to post on a server or to redistribute to lists requires specific permission and payment of a fee. Contact Publisher@InformingScience.org to request redistribution permission.
The expanding role of English as an international lingua franca has had considerable effects on higher education (HE) provision around the world. English has become the medium of choice for African $\mathrm{HE}$, and its position as a medium of instruction in the European context is strengthening (Coleman, 2006). Recent years have seen a "runaway expansion of English-medium programs" (HU, 
Integrating Content and English-Language Learning

2009 , p. 51) on the Chinese mainland, where government policy has actively promoted the establishment of English-medium courses at university level (HU, 2009). English-medium tertiary education is also commonplace in the Middle East including the United Arab Emirates (UAE), the context of the present study, where the vast majority of courses at university-level are conducted in English (Gallagher, 2011). The motivations for this trend are various and include a desire to facilitate cross-border mobility of academic staff and to attract international students (Coleman, 2006). However, a key consideration is also the employability of graduates. Reports dating from 2005 judge the vast majority of Indian and Chinese graduates to be unsuitable for employment in multinational companies because of weak spoken English skills (Graddol, 2006). Proficiency in a second language, generally English, is increasingly necessary for today's university graduates regardless of where they live.

While immersion models hold the promise of faster and more-effective language learning at lower expense and as part of mainstream education, caveats exist. The implementation of an effective bilingual program is much more than a simple move to using English in the classroom. Consideration must be given to an appropriate curriculum which takes language development into account as well as appropriate adaptations of teaching methodologies such that content can be delivered effectively in a second language (L2) (Marsh, 2008). Implementation of bilingual programs without due attention to these issues is likely to lead to "widespread school wastage... confusion, despair and high drop-out rates" (Marsh, 2008). Ill-considered implementation of bilingual programs, even where these are well-resourced, can and has sometimes ended in "fiasco" (Lasagabaster and Sierra, 2010).

The increasing use of English-medium programs presents particular challenges for content-area faculty who are in effect called upon to provide disciplinary instruction to students who may not be adequately language proficient. Furthermore, discipline-specific faculty may find themselves sharing responsibility to further develop their students' English language proficiency. This latter point largely motivates the formulation of this study which takes place in the College of Technological Innovation (CTI) at Zayed University (ZU), one of three federally funded HE institutions catering for Emirati nationals in the UAE.

Simply stated, CTI faculty are encouraged to substantively contribute to the further development of their students' English proficiency while meeting their primary charge of developing discipline-related skills and knowledge. Since furthering the development of English language ability poses a challenge for all programs at Zayed University, CTI faces unique challenges. A significant majority of CTI faculty come from computer science/engineering backgrounds and speak English as a second or third language. Most courses emphasize the development of technically oriented courses that afford relatively few opportunities for writing assignments. Nonetheless, the college takes its educational responsibilities seriously and has been working to improve students' use of English. While exploratory in nature, this study proposes to identify and evaluate practices that can help CTI better develop its students' proficiency in English.

\section{Issues in the Implementation of CLIL}

Content and Language Integrated Learning (CLIL) programs at secondary and tertiary levels are often judged on their ability to further language acquisition. Of paramount importance, however, is to ensure that the move to English-medium delivery of content does not impede acquisition of key concepts in the particular content areas.

The inclusion of learners at levels as low as A2 / B1 on the Common European Framework of Reference for Languages (CEFR) in some English-medium tertiary contexts has led to concerns that learning of content may suffer (Jiminez-Munoz, 2014). Studies in some secondary school CLIL contexts seem to indicate that students with lower language levels are more likely to under- 
achieve in their content courses, pointing to the possible existence of a language threshold below which learners' mastery of content would be compromised (Zydati $\beta$, 2012). Such a threshold seems likely to vary depending on factors such as mode of delivery and the nature of the subject itself; some subjects are considerably more language-intensive than others. For example, a management-oriented course is much more language-intensive than a computer-programming course; more reading and writing would likely be assigned in the former. Examining boards which administer popular "gatekeeper" exams suggest that minimum proficiency levels of CEFR low-B2 / 5.5 in the International English Language Testing System (IELTS) are necessary to follow tertiary courses of a language-intensive nature (IELTS, 2016). Studies in a tertiary CLIL context seem to show that where students are allowed to take English-medium, lecture-intensive courses with language proficiency levels as low as CEFR level B1 / IELTS 5, listening ability in particular can have some bearing on success (Breeze, 2014). Unfamiliar vocabulary seems to be a particular impediment to students' understanding of university lectures (Chang, 2010).

Given that many university courses are likely to have students with a range of English language abilities, it would seem vital that faculty involved in the delivery of content courses in a CLIL context carefully examine the methods they employ to support learners' achievement of key concepts. Faculty who see themselves primarily as experts involved in the transmission of knowledge may need to be sensitized to the particular difficulties faced by students in a CLIL context. Some simple techniques that may scaffold students' understanding of complex content include assigning pre-lecture reading in order to familiarize students with both the concept and the subjectspecific lexicon which will be covered (Chang, 2010) or the presentation of complex subjectspecific lexis prior to lectures or other (Breeze, 2014; Barbero and Gonzalez, 2013). However, it seems likely that in many CLIL contexts a greater sensitivity to the challenges faced by students as they process written and spoken English is necessary. To facilitate comprehension, texts used in content courses may need to be carefully chosen or specially adapted, and language used by faculty in lectures and seminars will need to be consciously planned and fine-tuned during delivery (de Graff, 2014). Sensitive use of visual support, and in particular visual organizers, can also scaffold comprehension of complex concepts (Bentley, 2010). Particularly where content is cognitively demanding, there may be a need to clearly contextualize concepts and link them to prior knowledge (Barbero and Gonzalez, 2013). Effective CLIL instruction also incorporates strategies to check understanding of concepts (Naves, 2009). It would seem, then, that considerable care and effort are necessary to ensure the effective delivery of content within a CLIL context.

In terms of language acquisition, there would seem to be general agreement that CLIL environments have the potential to promote naturalistic acquisition of a second (or additional) language because they involve students in meaningful communication in the additional language (DaltonPuffer, 2011; Naves, 2009; Jiminez-Muñoz, 2014; Swain, 2001). Several conditions may be necessary, however, for this potential to be realized. First, learners must be exposed to comprehensible input (Ellis, 1997; Naves, 2009; Gonzalez and Barbero, 2013; de Graff, Koopman and Weshoff, 2007). In practice, this may require considerable sensitivity on the part of instructors; key lexis may need to be presented in advance, language in texts used to input key concepts may need to be simplified, careful adaptation of language used in lectures and oral presentations may be required, and strategies to support and scaffold understanding will become vital.

However, while input should be both meaningful and comprehensible to promote L2 acquisition, attention to language forms (grammatical, morphological, lexical, phonological or discoursal) is also deemed necessary to this process (Ellis, 2005). In the context of the CLIL lesson, this attention to language forms might come about in two ways. Lessons might be designed to include either deductive presentation of language forms useful in subsequent spoken or written tasks, or inductive awareness-raising of useful linguistic constructions found in texts that have already been processed for meaning (Ellis, 2005). The clear implication here is that content lessons fol- 
Integrating Content and English-Language Learning

lowing a CLIL model would include an explicit language outcome, planned in advance, in addition to the intended content-related lesson outcome (Fortanet-Gómez, 2013). Attention to language forms might also be incorporated into lessons by focusing on errors present in learners' spoken or written output. Such corrective feedback might be implicit in nature (i.e., involving simple recasts or reformulations by the instructor or a more capable peer without exploration of grammatical rules) or explicit (i.e., involving metalinguistic discussion or explanation) (de Graff, Koopman, and Westhoff, 2007). This reactive attention to language forms implies that ample opportunity for learners to produce meaningful spoken and written output should be incorporated into the course (Swain, 2001).

\section{Cooperation and the Re-Defining of Roles}

The move to CLIL in a higher education context clearly involves considerable change and effort on behalf of content faculty involved. Development of appropriate teaching materials can prove highly time-consuming (Zegers, 2008). The onus on these content specialists to pay explicit attention to language issues may be unwelcome and challenging. In addition, university faculty around the globe are under increasing pressure to become more productive in the areas of research and administration (Fortanet-Gómez, 2013). It is perhaps not surprising that some faculty delivering content reject this revision of their roles (Lyster and Ballinger, 2011; Martín Del Pozo, 2013).

However, a paradigm that integrates work on language and content (e.g., IT project management) is also likely to take language specialists out of their comfort zones. Work over the past decade on academic literacy has focused on the relatively artificial nature of the work done in many freshman writing or composition courses, where literacy specialists, who are often working with students from a range of disciplines, promote unnatural discourse models not found in any realworld examples either within academic disciplines or in the wider world (Jacobs, 2005). Clearly, whether working on language support courses or supporting content faculty directly in materials writing or course planning, there is a need for language specialists to work toward a greater awareness of the actual discourse patterns their students will be expected to use in their disciplines.

Considerable effort, support and reorganization are vital to effectively implement CLIL in higher education so that content faculty are sufficiently supported and encouraged to play an active part. The relationship between language-support staff and faculty delivering content is seen as highly important to the success of this undertaking. Greater cooperation between these two groups over extended periods will be necessary to develop programs with explicit content and language goals (Zegers, 2008; Fortanet-Gómez, 2013; Martín Del Pozo, 2013, Pavón-Vazquez and Gaustad, 2013; Jacobs, 2005). The creation of materials that explore content in sufficient depth and complexity, while integrating effective support for language acquisition and the development of academic literacy, may also require close collaboration between language and content specialists; where these two groups work at arm's length, the resulting materials can contain a superficial and simplistic treatment of content or an artificial and less effective integration of language work (Fortanet-Gómez, 2013). There is general agreement that content faculty would benefit from training to improve their sensitivity to language issues and introduce methodologies which might address these issues (Fortanet-Gómez, 2013; Martín Del Pozo, 2013; de Graff, Koopman, and Westhoff, 2007; Jacobs, 2005). However, while English language specialists may be helpful in delivering such training, they should be receptive to input from faculty working in the disciplines. Effective English language training must take into consideration the discourse patterns of the particular academic community that students join over the course of their undergraduate study (Zegers, 2008). Content faculty are fully familiar with these discourse patterns, while language specialists may have only a superficial knowledge; however, language faculty are equipped with the 
skills needed to analyze these discipline-specific discourse patterns for the purpose of making them clear to students (Zegers, 2008; Fortanet-Gómez, 2013; Jacobs, 2005).

While close and extended cooperation between content and language specialists may be highly desirable in CLIL contexts, circumstances often mitigate against such a relationship. As mentioned previously, these groups can sometimes retreat into their narrowly-defined roles as language or content faculty (Lyster and Ballinger, 2011). It may also be the case that decisions at an institutional level mitigate against such cooperation. In-sessional discipline-specific language support courses can prove an ideal forum for cooperation between language and content specialists (Zegers, 2011). These language support courses may be more effective if they are implemented as full credit-bearing elements of undergraduate offerings, with formalized coordination at degree level between language and content specialists on each degree courses to ensure more effective cooperation (Pavón Vázquez and Gaustad, 2013). It must be pointed out, however, that these language support courses are often the first casualties when institutional budgets come under pressure and that the dedication of credits on an undergraduate program to a language support course may be controversial in some contexts. Finally, where cooperation between faculty in the disciplines and language specialists is initiated, it may be necessary to organize this in a manner that avoids perceived imbalances of power or status where one group appears to be tasked with changing the practice of the other with little or no reciprocity (Jacobs, 2005). As discussed above, effective integration is likely to mean considerable change for both groups.

The above literature strongly suggests that tertiary institutions offering CLIL or English-medium program models need to review current practice in view of the above findings and further examine pedagogical practices required to satisfy the dual objectives so that their students achieve required levels of disciplinary knowledge and language proficiency. For such institutions, disciplinary knowledge and language proficiency of graduates is integral to their reputations. While employer expectations may need some management in this respect (in many such institutions, native-like proficiency in a second language cannot be expected of graduates), more effort may be needed to ensure that graduates actually live up to institutional claims published in graduate outcomes, mission statements and other publicly available documents.

While several pedagogical paradigms have been developed to cater to classrooms with a dual content and language focus, this study will focus on the CLIL paradigm, as it most closely matches the ZU context:

- CLIL is associated with the use of an additional language (i.e., not the learners' first language (L1) or any other language generally used in the local context) as the medium of instruction in the classroom or lecture hall (Fortanet-Gómez, 2013; Dalton-Puffer, 2011).

- CLIL aims to provide "added value" by increasing proficiency in a second language "at no cost to other skills or knowledge, if properly designed" (Fortanet-Gómez, 2013).

- CLIL teachers often do not normally have native-like proficiency in the target language. Their background and experience is generally in a particular area of content, and they rarely have any background in the teaching of the English language (Dalton-Puffer, 2011).

- In the CLIL paradigm, not all courses are delivered in the target language (FortanetGómez, 2013).

- Unlike other models of bilingual education, the objective is increased proficiency in the target language, not balanced bilingualism where proficiency in L2 is comparable to proficiency in L1; this is generally not feasible under the CLIL model (Fortanet-Gómez, 2013; Lasagabaster and Sierra, 2010). 


\section{Framing the Research}

The present study takes place at Zayed University, a tertiary institution with extensive presessional language support. Credit-bearing in-sessional language and written composition courses are provided to students at the start of their undergraduate course work. These courses are of a generic nature and do not support specific disciplines. As students move through the later semesters of their programs, some colleges, such as the College of Technological Innovation, offer degree-specific, credit-bearing language support courses. These courses are sometimes delivered by language specialists working within the department, and in other cases by faculty "on loan" from the Department of English and Writing Studies. Some limited one-to-one assistance with writing is also available to students on demand. Content courses are delivered in English. There is little nor no coordination between language support faculty.

The ZU students are accepted into undergraduate courses with an IELTS score of 5.0 (ZU Catalogue, 2013). The trend among Emirati IELTS test-takers is toward stronger speaking and listening skills balanced by weaker writing and reading skills (IELTS Researchers - Test Taker Performance 2012 , n.d.), which may in practice mean that many students on undergraduate courses at the institution have levels of reading and writing well below those recommended for tertiary English-medium study. Added to the challenge of helping these students to successfully negotiate their content courses is the expectation that weaker students will gain proficiency over the three years they spend in undergraduate study. Cross-departmental learning outcomes dictate that " $\mathrm{ZU}$ graduates will be able to communicate effectively in English... using... academic conventions... appropriately" (ZU Catalogue, 2013). Thus content faculty are responsible both for improving English language proficiency and for assessing this proficiency as part of their course work.

While the faculty is well aware that a lack of English-language proficiency undermines content learning for a significant percentage of their students, until recently there was little evidence that the university recognized a system-level problem. In the 2014/15 academic year, the university acknowledged that a language proficiency issue existed at the college level; it directed CTI to formulate a program for improving student language skills and required the college to formally assess student development by requiring a sample of graduating students to retake English proficiency assessment: i.e., IELTS. The motivation for this research is that current initiatives in the provision of language support may not adequately reflect current thoughts on best practice.

The current study explores the difficulties encountered by CTI faculty delivering content at Zayed University in the context of an assessed written task. The tenets of CLIL will inform our investigations into ways in which both content and language specialists view student performance on written tasks. CLIL will also provide the lens for our framing and analysis of the data collected.

One approach is to incorporate language as a relatively minor element of assessment criteria so that language proficiency is rewarded, but poorer language skills are not overly penalized (Barbero and González, 2014). The current study attempts to examine how moves in this direction might be made, by looking at the following areas;

- Where subject specialists are asked to implement a language-related rubric as part of the assessment criteria for a piece of writing produced for assessment purposes in the disciplines, is the grading clear and consistent with the provided rubric?

- What are the reactions of subject specialists to the inclusion of a language-related rubric as assessment criteria for writing produced on their courses?

- Which issues do subject specialists identify that might affect the implementation of such an approach on a departmental or institutional level? 


\section{Methodology}

As the proposed study is action-oriented, the selection of study participants for this initial phase of research will be limited to current CTI faculty. We recognize this decision limits the formal generalizability of the findings beyond the research context. However, we believe we can provide sufficient description of the study context and method such that interested readers will be able to make informed decisions about whether the study findings are informative. As the study is exploratory in nature, we plan to refine our data collection methods as required and expand data collection beyond the initial study site.

The proposed study will employ multiple data-collection methods. The research team will conduct at least two semi-structured interviews with study participants. Additionally, participants will complete a structured survey instrument and participate in a grading exercise. The approach is briefly described below.

1. Conduct preliminary interviews to explain the purpose of the research, obtain consent to participate, and assess participants' views concerning newly emphasized responsibilities to actively contribute to developing student language and the appropriateness of this charge.

2. Faculty will participate in a marking exercise where they are requested to apply a predeveloped rubric to a small sample of student writings. In addition to applying the formal rubric, we will request that faculty provide samples of the type of feedback, if any, they would provide students if they offered such an assignment.

3. Finally, we will request that faculty participate in a follow-on interview and structured survey to capture their perceptions regarding the marking exercise. We are particularly interested in understanding faculty perceptions of self-efficacy when it comes to marking and whether they found the rubric helpful, and to obtain their suggestions regarding how the college might better help them support writing development.

To date we have completed developing the survey instrument, interview guides, and marking exercise. We are actively seeking study participants for the preliminary stage of research. Our intent is to be able to report the results from initial study participants at the conference.

\section{References}

Barbero, J., \& González, J.A. (2014). CLIL at university: Transversal integration of English language and content in the curriculum. In Breeze, Llamas Saiz, Martínez Pasamar \& Tabernero Sala (Eds), Integration of theory and practice in CLIL, Rodophi, Amsterdam, NY.

Breeze, R. (2008). Identifying student needs in English-medium university courses, in Breeze, Llamas Saiz, Martínez Pasamar and Tabernero Sala (eds) 2014, Integration of theory and practice in CLIL, Utrecht Studies in Language and Communication 28

Breeze, R. (2014). Identifying student needs in English-medium university courses. In Breeze, R. Llamas Saíz, C. Martínez Pasamar, C. \& Cristina Tabernero Sala. C. (Eds.), Integration of theory and practice in CLIL, Utrecht Studies in Language and Communication 28

IELTS. (2016). Test taker performance 2014. Retrieved from https://www.ielts.org/teaching-andresearch/test-taker-performance-2014

Coffin, C., Curry, M. J., Goodman, S., Hewings, A., Lillis, T. M., \& Swan, J. (2003). Teaching academic writing. Routledge

Coleman, J. A. (2006). English-medium teaching in European Higher Education. Language Teaching, $39(1), 1-14$

de Graff, R. Koopman, J. G., \& Westhoff, G. (2007). Identifying effective pedagogy in content and language integrated learning (CLIL). In U. Smit \& C. Dalton-Puffer (Eds), Vienna English Working Pa- 
pers, $16(3)$

Fortanet-Gómez, I. (2013). CLIL in higher education, towards a multilingual language policy. Multilingual Matters, Bristol, Buffalo, Toronto.

Gallagher, K. (2011). Bilingual education in the UAE: Factors, variables and critical questions. Education, Business and Society: Contemporary Middle Eastern Issues, 4(1), 62-78.

Graddol, D. (2006). English next. London: British Council

Hönig, I. (2010). Assessment in CLIL; A case study. In U. Smit, Schiftner, \& Dalton Puffer (Eds), Vienna English Working Papers (9)3.

$\mathrm{Hu}, \mathrm{G}$. W. (2009). The craze for English-medium education in China: Driving forces and looming consequences. English Today, 25(4), 47-54, CUP.

IELTS Guide for educational institutions, governments, professional bodies and commercial organisations. (2013). Retrieved from http://www.ielts.org/PDF/Guide_Edu-\%20Inst_Gov_2013.pdf

IELTS Researchers - Test taker performance 2012. (n.d.). Retrieved from http://www.ielts.org/researchers/analysis-of-test-data/test-taker-performance-2012.aspx

Jordan, R.R. (1997). English for academic purposes; A guide and resource book for teachers. Cambridge University Press, Cambridge, New York, Melbourne.

Lasagabaster, D. (2014). Content versus language teacher: How are CLIL students affected? In Breeze, Llamas Saiz, Martínez Pasamar, \& Tabernero Sala (Eds), Integration of theory and practice in CLIL, Utrecht Studies in Language and Communication 28.

Lasagabaster, D., \& Sierra, J. M. (2010). Immersion and CLIL in English: More differences than similarities. ELT Journal, 64(4), 367-375.

Marsh, D. (2008, 8 April). Adding language without taking away. Guardian weekly. Retrieved June $24^{\text {th }}$, 2014 from http://www.guardian.co.uk/guardianweekly/story/0,12674,1464367,00.html

Qi, D. S., \& Lapkin, S. (2001). Exploring the role of noticing in a three-stage second language writing task. Journal of Second Language Writing, 10, 277-303.

Salem, O., \& Swan, M. (2014, February 4). Foundation year at UAE state universities to be scrapped from 2018. The National. Retrieved from http://www.thenational.ae/uae/education/foundation-year-at-uaestate-universities-to-be-scrapped-from-2018\#ixzz35j2mkAv8

Song, M. J., \& Suh, B. R. (2008). The effect of output task types on noticing and learning of the English past counterfactual conditional. System, 36, 295-312.

Swain, M. (2001). Integrating content and language teaching through collaborative tasks. The Canadian Modern Language Review, 53(1), 44-63.

Van Leeuwen, C. (2006). From assessment anecdotes to learning practices. Bridging the assessment gap in English-medium higher education, 11-22.

Whittaker, R, Linares, A., \& McCabe, A. (2011). Written discourse development in CLIL at secondary school. Language Teaching Research, 15(3), 343-362.

Whittaker, R., \& Linares, A. (2009). CLIL in social sciences classrooms: Analysis of spoken and written productions. In Ruiz de Zarobe \& Jimenez Catalan (Eds), Content and language integrated learning; evidence from research in Europe.

Zegers, V. (2008). When European studies met English: A practitioner's view on content and language integrated learning. In R. Wilkinson \& V. Zegers (Eds), Realizing content and language integration in higher education. Maastricht University, NL. 


\section{Biographies}

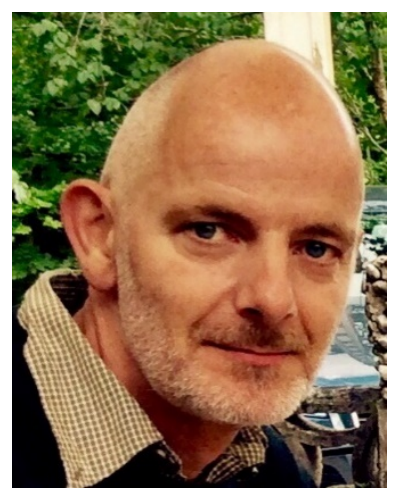

Norman Williams is an instructor and course coordinator in the Department of English and Writing Studies, University College, Zayed University, Abu Dhabi. He has worked with students for whom English is a second language for over 25 years and has worked on the design and delivery of English for Academic Purposes (EAP) courses in both the UK and the UAE. For the past 15 years, he has also been involved in training teachers of English as a foreign language at both pre-service and in-service levels. His main areas of interest are writing in academic contexts and reflection in both teacher training and undergraduate study.

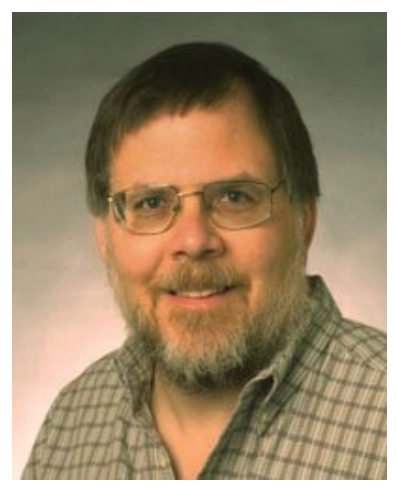

John C. Beachboard is a Professor of Computer Information Technology at the Zayed University College of Technological Innovation in Abu Dhabi, UAE. Previously he was a professor of Computer Information Systems at Idaho State University, USA. He has more than 25 years' experience implementing large-scale information technology and telecommunications systems and directing the U.S. Army's Data Network Control Center in Europe. He received an AIS Award for Innovation in IS Education for his work incorporating IT service management concepts in the CIS curriculum at ISU. He is the author of Peeling the Onion: IT Governance and Management for Business Managers. Dr. Beachboard's teaching and research interests emphasize practical approaches for delivering and operating secure, cost-effective IT services. He is a member of AIS, ACM and itSMF.

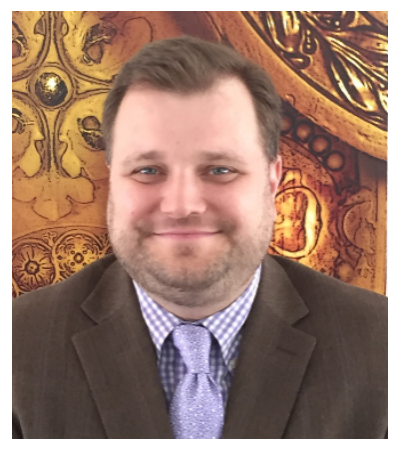

Robert Bohning is an instructor in the Academic Bridge Program at Zayed University in Abu Dhabi, UAE. Robert specializes in transitioning basic beginners and intermediate learners into academic contexts. He has more than 20 years of experience working in U.S. K-12 contexts as well as in intensive English programs in Missouri universities and community colleges. His main research interests are in second language writing and Mobile Assisted Language Learning (MALL). His additional research interests are in corpus linguistics, grammar teaching, second language acquisition, and content and language integrated learning (CLIL). 